\title{
Finding Ernesto: Temporary Labour Migration and Disabled Children's Health
}

\author{
Karen Soldatic, ${ }^{1}$ Helen Meekosha, ${ }^{2}$ and Kelly Somers ${ }^{1}$ \\ ${ }^{1}$ Centre for Human Rights Education, Curtin University, Perth, WA 6845, Australia \\ ${ }^{2}$ School of Social Work, University of New South Wales, Sydney, NSW 2052, Australia \\ Correspondence should be addressed to Karen Soldatic, k.soldatic@curtin.edu.au
}

Received 19 January 2012; Accepted 22 February 2012

Academic Editor: Cherylynn Bassani

Copyright (C) 2012 Karen Soldatic et al. This is an open access article distributed under the Creative Commons Attribution License, which permits unrestricted use, distribution, and reproduction in any medium, provided the original work is properly cited.

\begin{abstract}
We seek to expose the implications of Australia's exclusionary and discriminatory disability migration provisions on the health and wellbeing of disabled children who have arrived in Australia through alternative migratory routes. By undertaking an in-depth analysis of a single case study, Ernesto, we bring to the fore the key issues facing disabled immigrant children. These children, like our case study Ernesto, are only granted visas on the proviso that their parents/primary caregivers agree to cover the full costs associated with their disability, including medical care and additional expenses such as educational inclusion. The story of Ernesto reveals the extreme impact of these discriminatory policies on this population's health and wellbeing. Further, we discuss how the state's "right to exclude" people with disabilities from the migratory process negatively affects the health and wellbeing of their siblings and parents.
\end{abstract}

\section{Introduction}

Disabled immigrant children, including refugees, rarely receive attention in the international research. The omission of this group from the international literature is, however, not surprising given that nation states have readily implemented a range of legal measures to effectively disallow either the temporary or permanent entry of disabled people across their borders [1-3]. Australia is no exception to this long-standing international trend, and since the inception of the Immigration Restriction Act (1901), disabled people (adults and children) have been actively excluded from the Australian migration process [4]. This process of exclusion has remained unchanged despite numerous changes to both migration and disability discrimination law [5]. The Migration Act of 1957 was explicitly exempted from the passage of the Disability Discrimination Act in 1992 [6]. Any migrant to Australia, even those granted international refugee status via the United Nations High Commissioner for Refugees, must meet the Health Requirement, for which a cost-benefit assessment of a health condition, under which disability is defined for migration purposes, is factored into a visa decision. While all applicants are required to endure this "health test" as a condition of entry, disabled people are considered to be "exceptions to the rule" where the Australian government automatically calculates and applies a maximum health cost as a means to activate its right to exclude certain potential migrants from the Australian polity [5] (see [7] for a full discussion of this point).

Over recent years, there has been a limited number of empirical studies that have directly evaluated the impact of these exclusionary policies on disabled people and their families (see $[2,4]$ ). These studies have found that disability of one member impacts the health and wellbeing of all family members involved in the migration process. Rather than this being directly due to the health status of the disabled family member, it is largely due to the way in which disability is situated within Australian immigration policy.

The disabled child appears to be particularly disadvantaged within Australian immigration policy. In nearly all of the recent high-profile cases cited by the media, it has been the disabled child that has been rejected for permanent Australian residency on the grounds of disability [8]. As Natalier and Harris-Rimmer point out, the heightened level of disadvantage experienced by disabled children under the Australian Migration Act is due to the cost calculation 
system that determines residency eligibility [9]. This can be seen as a type of "triple jeopardy" where a disabled child faces additional barriers due to the intersecting factors of disability, age and migration. The "cost of disability" calculation framework within the Australian Migration Act assesses the child's potential costs in terms of health services and costs of other social supports across the life span of the child. Natalier and Harris-Rimmer suggest that these assumptions make the disabled child appear as an enormous economic impost upon the Australian public system given the assumed additional years of health, education and social services that are included in this assessment [9].

As a result, disabled children rarely make it through Australia's immigration system [5]. Migrating families, particularly those from the global South, are often forced to make the extreme decision of leaving their disabled child behind to guarantee their own and other family members' chances of migration [5]. The population of temporary migrant workers in Australia is but one category of migrant that is affected by the "health test." As Mirza has argued elsewhere, disabled refugees are rarely considered for resettlement in countries such as Australia, despite their higher level of vulnerability when remaining in refugee camps [10]. The cost-burden argument of disability as a drain on the healthcare and social service systems reflects and further embeds prevailing negative attitudes toward disability within "mainstream" populations $[11,12]$-a key reason for the Australian government in maintaining its discriminatory immigration policy, despite extensive community advocacy to have this overturned [5].

Despite this broader sociopolitical context and the resultant exclusionary migratory policies towards disability, there are some children who "make it to Australia" via alternative migratory routes. In nearly all instances, the disabled child is part of a family unit that is considered eligible for short-term entry as the parents have been given temporary migration status, commonly in the category of a skilled guest worker. As Ciupijus suggests, there are significant moral dilemmas associated with temporary labour migration systems [13]. A range of severe social inequalities exist which are maintained by such a system due to "the class subordination of immigrant groups and higher profits both for employers and the nation-states [which are] achieved by passing of labour renewal costs (accommodation, travel, training and welfare) to migrants and their families" [13]. In Australia, migrants wishing to claim the Disability Support Pension must be resident for 10 years before becoming eligible, while family members of a person with disability must be resident for two years before being able to claim the Carer Payment [5]. The ongoing perpetuation of broader sociostructural inequalities through temporary migratory labour programs has long been recognized in the international literature (see $[14,15]$ ).

While guest worker programs are presented as a winwin situation whereby the workers, their families, the host countries, and the countries of origin all gain, there is clearly a risk in compromising human rights. In Australia the Temporary Business (Long Stay) visa, also known as a 457 visa, was introduced in 1996 with the purpose of allowing employers to sponsor workers on a short-term basis
[16]. Concerns about this visa category raised by community organizations and the Australian Congress of Trade Unions have centred around wage and salary rates, English-language skills and qualifications, and employer compliance [17]. One serious social consequence of the 457 visa system relates to disabled children of the visa holder. While primary and secondary holders may have access to health services via employer insurance policies, children who are disabledand thus have "pre-existing medical conditions"-have no medical protection nor access to disability-related services. This appears to us to be in breach of both the UN Convention on the Rights of the Child and the UN Convention on the Rights of Persons with Disabilities. A 2008 review into the integrity of the 457 visa program recommended that workers in this category be given Medicare coverage, allowing them and their dependants access to the public health system, though the government is yet to respond to the report's recommendations [18].

A significant body of research navigates the impact of temporary labour migration systems on the health and wellbeing of the children of such families [19, 20]; but, as Berman suggests, it still remains largely underdeveloped [21]. Despite the growing interest in the area, there is scant empirical research that seeks to elucidate the impact of temporary labour migratory systems on the health and wellbeing of children who are disabled and migrate temporarily with their families.

In this paper, we begin to fill this significant gap in the literature by critically engaging with a single-site case study of a recently arrived temporary migrant worker family in Australia. As the case study exemplifies, the intersectionality of temporary migration, age and disability results in a web of complex issues and barriers which, in turn, affects not only the health and wellbeing of the disabled child but also has repercussions onto other family members. We suggest that the analysis adds a new dimension to the field of child migrant health research and practice. We attempt to critically examine the contradictory discourses, practices, and effects of temporary migrant labour programs on the various migratory categories that intersect with disability.

Bedolla's discussion on contemporary developments in theories of intersectionality is suggestive of the ways in which single analytical categorization acts to hide the heterogeneity of a group and the "crosscutting political effects of both marginalisation and privilege within and among groups" [22]. In the field of child migrant health research, disability is clearly a marginalized category. We seek to draw attention to the uneven effects of disability on complex intersecting child migrant identities as a means to encourage greater research in the area.

\section{Methodology: The Single-Case Method}

As discussed above, in this paper we draw upon a singlecase methodology to reveal the complex intersecting factors that impede the health and wellbeing of disabled children of temporary migrant workers and the resultant impact on their able-bodied family members. The family and their child 
Ernesto (a pseudonym) first came to our attention when one of the researchers (Soldatic) visited a rural town in the north of Western Australia as part of a large national study funded by the Australian Research Council on disability in rural Australia. While targeting other disability population groups, including indigenous Australians with disability living in rural and remote parts of the country, the original methodological framework of the research had not captured disabled children on temporary migrant worker visas. In fact, we too, as disability researchers, had omitted this group from our original framework and admit to a clear oversight. On arrival in the rural town to carry out the project, we were encouraged by local disability advocacy groups to meet with Ernesto and his family. The local advocacy groups had not come across a situation like Ernesto before within a rural setting but felt, and we now agree, that Ernesto and his family provided a critical window into exploring the intersectionality of temporary migration, disability, childhood, and health. After initial discussions, we agreed that Ernesto and his family's participation could be readily included in the study and that they provided a pertinent contribution to current debates within Australian public policy-both in terms of temporary migratory visas for guest workers and the implications of disability exclusion within migration law and policy. Several field sites across Australia have been visited as part of the research project and, to date, Ernesto and his family are the first to emerge in this visa category. Considering the fact that two of the researchers have extensive practice and research expertise in the intersecting fields of immigration and disability $[2,3]$, this experience appeared to make clear that temporary migration status and its impact on disabled children are an invisible area within disability, immigration, and health research. While historically there has been criticism of the limitations of the single-case method within the health sciences, there is growing recognition of the power of this methodological approach to greatly inform health research for various population groups [23]. The single-case method, as Sayer suggests, provides the researcher with the opportunity to investigate the phenomenon under study in all of its particularities and complexities [24]. This particular in-depth case study revealed several complexities that have not been discussed in any of the research on disability, immigration, or health. The issues faced by Ernesto and his family are unique to the category of temporary migrants. Our example supports the growing recognition that the single- site case study provides a rich contextual environment allowing deeper exploration of the issues that arise. Further, the themes arising from our discussion with Ernesto's family, particularly in relation to family stability, gaps in insurance coverage, and the implications for Ernesto's health and education are mirrored in the issues that have emerged from government inquiries into temporary migration. Thus, while the findings of the single-site case study are nuanced, they appear to be shared across a spectrum of populations that have in common their temporary migrant status as guest workers [25]. The richness of data that comes through such intensive empirical investigation increases our capacity to understand the implications of policy at the level of implementation and practice [26].
Patton argues that this method should be used in association with hard-to-reach populations given their heightened level of invisibility within the research field [27]. We suggest that Ernesto, the disabled child of a temporary migrant worker family who arrived in Australia in early 2011, exemplifies these necessary analytical conditions. Having extensively searched the literature, we found that the impact of Australia's migration policy on the health and wellbeing of disabled immigrant children appears to be largely underexplored. This is further intensified once the lens of temporary migration status intersects with the two broader categories of disability and children. Given these extenuating conditions, despite the initial limitations that the method may appear to hold, in-depth qualitative analysis of a single-site case study can clearly identify trends and consistencies emerging within the broader specified sample population [28].

\section{Coming to Australia: Contesting Official Rhetoric}

At the time of the research in late 2011, Ernesto, an eight-year-old boy from the Philippines, had been living in Australia with his younger brother, his mother, and father for approximately six months. Ernesto was born with cerebral palsy and had two operations within the first eight months of his life, including the insertion of a cerebral shunt to treat infant hydrocephalus at approximately eight months of age. Given the severity of the operations, Ernesto was hospitalized for several months at a time. While living in the Philippines, Ernesto's mother provided full-time care, accepting primary responsibility for Ernesto's daily care needs with the help of relatives and friends living close by. Ernesto's father, since graduating with a Bachelor of Science in Hotel and Restaurant Management, has worked extensively in international hotel management as a temporary migrant worker. It is this history of working as an international migrant worker that provided the opportunity for the family to move to Australia. His previous employer offered Ernesto's father temporary employment as a manager in one of the organization's international tourist resorts in rural Australia.

Despite Ernesto's father's working background as a transitory migrant worker, Ernesto, his mother, and younger brother had always remained in the Philippines. Temporary migration to Australia was the first time that the entire family had considered such a move, and, in turn, the family's decision to migrate to Australia temporarily involved extensive deliberation of a number of issues. The most significant consideration in these family discussions, however, surrounded the provision of health care and disability supports for Ernesto, as his father articulates:

I came to Western Australia first for actually two years before they arrived because they just arrived six months ago. The reason why I did that one is because I wanted to settle in first and see how it goes. How the life goes on here, you know because I have a special son. I just wanna know how we gonna survive here in [rural town] especially when the young fellow gets sick. So that's one of the 
concern that I got. Just make sure that we gonna live in [rural town]. If I bring them altogether, we gonna struggle in the first year.

As this narrative suggests, deciding to migrate temporarily under Australia's skilled migration program for families with a disabled child is a difficult decision for all members. In this particular case, it resulted in a lengthy period of separation of almost two years. Both parents felt that this was necessary to ensure the long-term health and wellbeing of their disabled child despite the encouragement from the father's employer to move the family across from the Philippines within the first 12 months of arrival, as Ernesto's father states:

Our employer said we can apply for our visa when we are in our first year over here but we did not do that because we still not stable in here. I'm not really keen to bring them here.

The theme of family stability, as a critical component of ensuring the long-term health and wellbeing of Ernesto, dominated his parents' narrative and was articulated as their overriding concern throughout the interview. Interestingly, this strong narrative on issues of family stability contests the dominant assumption underpinning the Migration Act that families with disabled children want to migrate to Australia, temporarily or permanently, to gain access to the country's public health system [5].

The theme of family stability was coupled by a subtheme of embedded local networks and the critical role these networks play in navigating healthcare systems for disabled children. As Ernesto's parents suggest, there are certain privileges that come from being embedded in your own local community which play a vital role in accessing local health services both immediately and in the longer term. As the parents identified, residing in your home country means that you have a degree of social capital within your local community, such as personal networks, which allows for a certain level of privilege. The family resided in a small rural Filipino village approximately 16 hours' drive out of Manila. Being part of this small local village meant that they were well established in their own community and could therefore draw on these networks when necessary. Ernesto's mother points this out when she states that:

That's why when we came here it was really a big adjustment. I had my siblings and the doctors, like the neurologist and the pediatrician, were close family friends so sometimes they did not charge us. So before coming here they asked us many times "Are you really sure you want to bring your son?"

Ernesto's father also reflected on the central role of local supports that are attained through long-term friendships and family networks, and how this can provide a level of security for the family with a disabled child, particularly economically, as they can gain access to the required health care when needed: Like in the Philippines we can just get the medical attention for cheaper sometimes or for free because we know the doctors and there's like family friends and stuff so we save lots of money with them.

Family stability and having local networks to support their negotiation of the healthcare system were two crucial considerations for the family when deciding whether to temporarily migrate. This, of course, appears to contradict internationally accepted understandings of the benefits of temporary migrant labour. Lutz posits that temporary labour migration has been promoted by western governments and global policy institutes (such as the OECD, IMF, and World Bank), which frequently present it as facilitating significant long-term economic security for temporary migrant workers and their families in their country of origin, particularly those families who come from the global South, such as Ernesto's [29]. Further, it is frequently cited as a pivotal form of wealth production for the development of the workers' countries of origin, due to the return of international remittances [30]. As an example, a recent Canadian government report argued that guest workers benefit as "many workers earn much more in Canada than would be possible in the country of origin. These earnings are significant sources of income for family members left behind" [31].

However, these arguments do not necessarily reflect the way in which having a family member with disability appears to negate the so-called benefits of such programs. While employers of temporary migrant workers in Australia are required to ensure that these workers are covered with a range of insurances, including insurance for health care, these insurances are not structured around the needs of disability. While disability insurance, as a part of the health economics school, is an area that has received considerable attention in the international literature [32, 33], there has been little consideration of the intersecting factor of temporary migrant labour within the research.

From the interview with Ernesto's family and their experience of the Australian immigration process for their disabled child, we could surmise that this could be partly due to the invisibility of disability. The level of invisibility is reinforced for temporary migrant workers as they are required to agree to sign a health cost waiver prior to the granting of a visa to ensure that the family covers any health costs associated with the disabled family member. As Ernesto's father explains below, families with a disability taking part in a temporary labour program are required to meet a range of demands prior to the issuing of a visa. In terms of Australian immigration, a key component is a demonstration of available personal financial resources to cover the full costs of the child's health care while in Australia.

Father: Plus I need to go through a very strict processing because of my special son. For me to process my visa for my special son it takes six months. Six months of drama.

\section{Researcher: So what do you mean by "drama"?}

Father: Well first of all they send me a waiver that I need to pay ... for my son ... just to bring him here. ... Just to bring my son over here. Just to 
cover his medical expenses. I don't even earn that money within a year.

Given these strict requirements, the so-called benefits for guest workers, as espoused by global policy institutes and western governments, do not encompass temporary migrant workers who have disability within the family unit. An important theme to emerge from this case study is the dubiousness of the claim that temporary migrant workers benefit from these arrangements, despite the fact that they are exempt from receiving any assistance from national healthcare or social welfare systems. This disadvantage is further compounded when the family includes a child with a disability, where the disabled child is negatively valued by the Australian government in its determination of the potential costs of providing health care and other social services. Ernesto's family's experience of the barriers faced by the parents of disabled child migrants does not appear to be unusual when reviewing numerous cases that have received media attention or been submitted to the Australian Senate Inquiry [5]. In many instances, it has been only through strong local community support and advocacy that these families have been granted entry visas [34]. In fact, it was through the advocacy of health professionals that temporary immigrant status was granted to Ernesto, as his father explains:

So it's crazy but suddenly my boss's sister is a nurse
and she is the one who speak with Immigration,
and argue with this one. She knows what's going
on-she's a good nurse-and she managed to
speak to Immigration and asked them to explain
it to her why we need to pay for that one and
suddenly the Immigration is just like making it
hard for me.

Even with this support and advocacy, there appears to be a degree of coercion in the administration of immigration policy to ensure that guest workers who have a family member with disability comply with the restrictions. As Ernesto's mother explained, the Australian government issued her own visa along with Ernesto's younger brother's visa; however, it did not offer a temporary visa for Ernesto to travel with the family.

The first time we lodged our application me and my younger son had our visas straight away. With Ernesto there were a lot of issues. So we filled a petition and on his birthday we received a letter saying that he got his visa. We had a neurologist do a check-up saying that he had to continue with his therapies and that it wasn't like tuberculosis.

As Ernesto's mother's dialogue suggests, there is a strong tendency to conflate "disease" with "disability" in the administration of the visa application assessment. It has been very problematic for temporary migrant families despite the ongoing expansion of the Australian government's temporary labour migration program. Gothard and Fox have noted the remarkable measures that families have to endure to have their disabled child's case considered [34]. Further, the disabled child's visa is generally granted on the perceived value and benefit of the parent, rather than the disabled child, to the Australian community [34]. The conflation of disease with disability has remained unchanged [35], despite the extensive recommendations by the Senate Inquiry of 2010 to address this very issue (recommendation 4, page 58) [5]. The Australian government is yet to respond to these very recommendations [8].

\section{Counting the Costs}

Throughout the interview, it became clear from the parents' narrative that the status of temporary migrant worker with a disabled child caused numerous health implications for the entire family. This was primarily associated with the extensive restrictions of entry enforced upon Ernesto and his family while residing in Australia and the extensive limitations of temporary worker insurances which are supposed to be mandatory for 457 visa category holders. The signing of a waiver as a means to ensure that the family covers the full healthcare costs for their disabled son has created a range of hardships, despite the relief that insurance is supposed to provide. Ernesto requires medical food products as he is unable to swallow hard food. Availability of these specialized products is only through the local hospital system and while other disabled children in Australia have access to these, the family, as temporary migrant workers, are required to spend an additional \$A250 per month on such items. As Ernesto's father suggests, this undermines any of the so-called benefits awarded to temporary migrant families with a disabled child:
Normally it depends. Sometimes he drinks the milk really fast and one carton is not enough. So it's $\$ 250$ and that's only for my special son. But my other son-normally we spend at least $\$ 150$ for him for a month. So pretty much all of the money that I'm earning is just going to the bills and there's nothing much left for the savings actually.

While the stress of such a process has clear implications for the health and wellbeing of all family members, one of the social determinants of health for disabled children of temporary migrant workers is the role of insurance in covering the costs encountered when negotiating Australia's health system-both public and private. One of the conditions of entry for temporary migrant workers under the Australian system is health insurance. These insurance schemes, while promising to relieve the high costs of Australian medical care for temporary migrant workers, are in fact confusing.

These specialized food products, according to the family, are not covered under the temporary migrant worker health insurance scheme. In fact, the family has had a range of issues pertaining to the insurance that they were originally awarded under their employment. While in Australia, Ernesto has had several health issues emerge due to the change in the environment for which he has had to be hospitalized. Despite the reassurances from the original insurance company, many of the costs were not covered, leaving the family with a significant monthly healthcare bill which has yet to be paid. 
Father: The first health insurance that I have was so crap. I paid for three months and by the time that I tried to get the claims-the claims were at least $\$ 1000$ - they does not wanna give that one to me unless I pay the monthly bills. I contest that one because every time I ring them, they saying different answer to me which is not really consistent. There's some operators saying that "yes we can just reimburse the money that you're claiming and pay that one off". We ring on the second time, they say "No you need to pay it first before we reimburse it". Then we asked them why suddenly someone say that one to us and suddenly they send us a letter saying they cannot settle our health insurance and stuff, which is not good.

Given the ongoing issues with the original company, the family decided to move to a new insurance firm. The insurance coverage was slightly more extensive, including the costs of an occupational therapist; however, it was much more expensive. The family decided that this was a necessary financial burden to ensure that Ernesto received at least some of the occupational therapy required for his development.

Father: No I just get the second to the top one which cost me $\$ 400$ a month. It's a bit expensive though but I picked that one because at least that one covers lots of everything that we always need, like hospitalization and stuff like that and checkup. So they cover all of those.

At the time of the interview, however, this new insurance coverage had yet to pay out the costs of Ernesto's more recent hospital care. This proved to be particularly stressful, as Ernesto had recently had a fall and as a result required a splint for his right arm. This splint, while supplied by the hospital, again had yet to be paid. Ernesto's father explained that: We are working on the splint that we have two months ago. We need to pay for that one.

While the family cited several instances of Ernesto requiring hospitalization and the financial burden, this created another major concern for the family which was the lack of access to additional therapies that were necessary for Ernesto's development. The insurance that they now received, while improved, only appeared to cover the costs of accessing an occupational therapist. However, Ernesto, given his stage of development, required both the support of a physiotherapist and a speech pathologist. As Ernesto's father notes: He only got the occupational therapist on my health insurance. But he's supposed to be having physio and speech and occupational therapy. As both physiotherapy and speech therapy are not available via the insurance coverage, Ernesto remains without these essential services as the family is not in a position to afford these also. At this stage, it remains unclear what the long-term effects will be on Ernesto.

There is no doubt that the signing of a required immigration waiver for Ernesto has had the greatest impact on the family. The family's medical debts were averaging around $\$ 1000$ per month over the three months prior to the interview due to Ernesto requiring visits to specialists and hospitalization. As the promise of insurance coverage had not eventuated in practice, Ernesto's mother had begun some part-time work to help pay for the additional costs of health care that the family were facing. However, the work was intermittent and extremely precarious. Additionally, as the family had no family members or friends to rely on for their children's care, the parents worked at either ends of the day. Ernesto's mother worked early mornings, from 7am through to $2 \mathrm{pm}$, and Ernesto's father worked from $3 \mathrm{pm}$ to late in the evening. At times, due to the demands of his work, Ernesto's father reported working an average of six or seven days per week with each shift generally encompassing more than eight hours. At the time of the interview, both parents were extremely tired due to the long hours of work and the juggling of care responsibilities for both children. Given the significant stress that such demands create, it was not surprising to learn during the interview that Ernesto's mother had been recently hospitalized overnight due to infection, leaving the full care of both children to Ernesto's father.

Another theme to emerge under the broad banner of insurance was that this coverage also did not take into account necessary disability supports for educational inclusion. In Australia, early intervention therapies for children are also administered through the education system. In many instances, students receive many of their required therapies while at school. The prescribed therapist will attend to the child while at school as part of an integrated educational framework to promote the educational inclusion of disabled students. However, due to Ernesto's parents' temporary migrant status, Ernesto did not qualify for such services (see [36]). Even though the parents had met with the principal of the local public school, no one, including a local disability advocate, had been able to ascertain whether Ernesto would be able to enrol. Nor had anyone been able to verify if Ernesto would qualify for early intervention services, available at the local school, should he enrol. This level of confusion surrounds the status of their temporary visa and the availability of public health and social programs and whether the temporary worker insurance would cover such therapies. Outside the school system, it is clear that Ernesto is ineligible for disability services. But it remains unclear if this is also the case if it effectively results in the denial of a right to education. As a result of this confusion, since arriving in Australia, Ernesto has been effectively excluded from the education system.

The immediate effects of such insurance limitations under temporary migration law pertain both to Ernesto's educational development and his potential to reach developmental milestones in terms of his access to early intervention therapies. In addition, there is extensive empirical data that acknowledges the substantial health benefits for disabled children of socially engaging with peers [37], which would be negated by Ernesto's not being able to attend school. Thus, there is no accurate way to calculate the probable implications for Ernesto's health and wellbeing, given the ongoing denial of essential therapy services for his long-term development (see [38]). 
In all, these additional incurred costs, created through the enforced signing of a health cost waiver and the limited coverage of mandatory temporary worker health insurance, have also had implications for the family in terms of finding affordable and adequate housing. During the first two years of his stay, Ernesto's father lived with other workers in a house owned by his employer. With the arrival of his family, they moved into a large converted shed at the back of the house. We visited the family to conduct the interview. We found a converted shed which contained a small kitchen with a small extended area used as a family sitting area. There was a bathroom and a single bedroom which the family shared. The ongoing cost of hospitalization, the medically prescribed food which Ernesto consumed, and additional therapies meant that the family were unable to rent more suitable family housing. Despite the promise of insurance schemes to cover the healthcare costs of temporary migrant workers and their families, these were, in effect, extremely limited. In turn, the family's health and housing situation were directly affected.

\section{Goodwill of Disability and Health Professionals and Practitioners}

Maintaining Ernesto's health in the six months leading up to the interview had been dependent on the goodwill of local disability professionals and medical staff. It had been only because of the goodwill of health and disability professionals throughout their stay that the family had been able to remain in Australia. In fact, the goodwill shown by these professionals was the only positive theme to emerge from the interview. These local professionals were central to the family's decision to temporarily migrate to Australia. While necessary information was initially obtained through some of Ernesto's father's colleagues, these networks had been extended to incorporate a range of other health professionals who had been instrumental in maintaining Ernesto's access to the health and disability systems despite the substantial barriers the family had confronted. One of Ernesto's father's colleagues was able to put the family in contact with the disability district officer in the region, and his employer's sister-in-law, as mentioned earlier, was a locally employed nurse. These professionals were instrumental on two fronts in shaping the family's decision to migrate to Australia. First, they provided the necessary information on the availability (if any) of disability services in the local area and second, as outlined previously, the nurse actively supported Ernesto's application through the immigration process. It is because of these relationships that Ernesto's family decided to all apply for temporary migration status under the temporary skilled migration program.

Unfortunately, the regional disability district officer was unable to support the family as they did not qualify for government disability assistance due to their visa status as temporary migrant workers. However, as the family explained, this officer made numerous referrals to ensure that the family was at least supported by the local disability advocate, who worked for a local disability nongovernment provider. As the family identified, the goodwill of local professionals was being maintained; however, it had to be presented behind a façade to ensure that it appeared they were working within the rules of the system:

Father: He [the disability district officer] can't do anything yet because we don't have our residency but he source it out. Like we need to speak to [local disability advocate] now not to him and then she speaks to him. So he is finding ways to give us a hand.

The goodwill of a range of health and disability professionals had been critical to ensuring Ernesto's ongoing access to essential services and supports. The family was fortunate to make contact with health staff, including public health specialists within the hospital system, who overrode the strict immigration requirements and developed alternative routes for Ernesto's health care, as the father explained:

We met so many people already in the hospital which is giving us a hand and sometimes we get the consultations for free which is good. They know that we are on 457 [visas] and they know that every time we see them, we gonna pay $\$ 200$. So they understand the situation so sometimes they just say, "Don't go there just go over here in my clinic straight away, and we'll do the stuff and don't bother anything to pay". So that's good. Even the staff on the Allied Health, they also do that one, like "We'll sneak him in". But if we been noticed by anyone, of course \$200 again. So they know the situation which is good. They still willing to give the benefits and stuff. They know that it was so unfair for us.

The local disability advocate had also assisted the family in arranging a specialist visit in order to get an appropriate wheelchair for Ernesto.

Father: And [disability advocate] said if we can also include in the application a wheelchair. We got a wheelchair from the Philippines but it's broken already. It was made by disabled people in the Philippines but it's pretty heavy - it's 25 kilos.

Researcher: So what you're looking for is a lighter $\ldots$

Father: It's not really lighter. As long as it fit on my son and he can sit properly.

Researcher: And do you know how much the chair will cost?

Mother: They don't have any idea yet. There'll be somebody who's coming down from Disability this weekend. From there they will know what kind of wheelchair will he need and they can have the right quote for that one. 
With the advocate's encouragement and assistance, the family had applied for funding from a local charity to help cover the costs of the new wheelchair. At the time of the interview, they had been using a pram to transport Ernesto which was uncomfortable, too small for him, and in which he had to be pushed by a family member. Having a suitable wheelchair would not only improve Ernesto's comfort and ability to get around, but would also mean that he could go to school, enabling him to fulfil his right to education and potentially giving him access to the therapies he requires.

As the above examples show, the family has relied heavily on the goodwill of their colleagues and community in order to access the health and disability support services that Ernesto needs. Nongovernment service providers, community members and advocates, and even government workers acting "unofficially" have stepped in to fill the gaps in support that have not been covered by the government or even the family's private health insurance. Though in moving to Australia the family had lost the personal networks and solid ties with their local community in the Philippines that had helped them to care for Ernesto, the community in their host country came together to help them overcome the barriers to accessing support and advice. This can be seen as yet another example of community support to have the Australian government's discriminatory migration policy overturned.

\section{Conclusion}

Though the Australian government has ratified the United Nations Convention on the Rights of Persons with Disabilities, its most recent commitment in the area of human rights conventions and treaties, it has applied a number of legal interpretations to separate and segregate disability from immigration policy, sidestepping its international obligations [2]. The imposition of such an interpretive clause, as our case study reveals, may have significant implications for the health and wellbeing of all immigrant populations as both disability and health services have had little historical exposure to this group's needs, particularly when first resettling in Australia [39]. This becomes further evident when we consider that recent data analysis of disability within Australian immigrant populations clearly suggests that it is these communities that are the most likely to experience the early onset of disability, which is partly attributed to the resettlement process itself [40].

Over the years there has been much lobbying by ethnic communities and disability organizations to address the injustice faced by both refugee and immigrant families in attempting to challenge government policy on disability. It is tempting to be pessimistic about the situation of immigrant families with disabled children. Yet we have seen advances in both government and civil society thinking about disability in other areas in recent years. Disabled people are no longer seen as simply a burden on the taxpayer and families. They are seen as agents in their own right who have the capacity to undertake education and employment, and to experience satisfying and fulfilling lives. Increasingly, disabled people are recognized for their contribution to the broader society.

Unfortunately, this thinking has not been transferred into immigration and refugee policy. We need to see substantial and major shifts in thinking at this level, where it cannot be left solely to ethnic and disability groups to push for change. Civil society groups and community groups have an important role to play, as well as critical work by academic researchers and teachers. Stories such as that of Ernesto and his family will hopefully have a role to play in informing changes in immigration policy.

\section{Acknowledgments}

The authors would like to thank Ernesto's family for welcoming them into their home and for sharing their story with us for this research. They would also like to thank the advocate at Kimberley Advocacy for introducing us to Ernesto and his family and to Ethnic Disability Advocacy Centre for their ongoing support for this research. The writing of this paper has been supported by an Australian Research Council grant (Disability in Rural Australia), a British Academy International Fellowship and a Curtin University Research Fellowship.

\section{References}

[1] Y. El-Lahib and S. Wehbi, "Immigration and disability: ableism in the policies of the Canadian state," International Social Work, vol. 55, no. 1, pp. 95-108, 2012.

[2] K. Soldatic and L. Fiske, "Bodies 'locked up': intersections of disability and race in australian immigration," Disability and Society, vol. 24, no. 3, pp. 289-301, 2009.

[3] A. Jakubowicz and H. Meekosha, "Bodies in motion: critical issues between disability studies and multicultural studies," Journal of Intercultural Studies, vol. 23, no. 3, pp. 237-252, 2002.

[4] G. Goggin and C. Newell, Disability in Australia: Exposing a Social Apartheid, University of New South Wales Press, Sydney, Australia, 2005.

[5] Joint Standing Committee on Migration, Enabling Australia, Inquiry into the Migration Treatment of Disability, Commonwealth of Australia, Canberra, Australia, 2010.

[6] B. Howe, Ministerial Statement: Social Justice for People with Disabilities, House of Representatives Hansard, 1991.

[7] J. Seglow, "The ethics of immigration," Political Studies Review, vol. 3, no. 3, pp. 317-334, 2005.

[8] ABC News, Push to change law for disabled migrants, 7.30, Australia, December 2011, http://www.abc.net.au/news/201112-08/push-to-change-law-for-disabled-migrants/3721248.

[9] K. Natalier and S. Harris-Rimmer, "Counting the cost: the social construction and human rights conceptualisation of the disabled child migrant through Australia's migration processes," in Proceedings of the Annual Conference of The Australian Sociological Association, Canberra, Australia, 2009.

[10] M. Mirza, "Unmet needs and diminished opportunities: disability, displacement and humanitarian healthcare," New Issues in Refugee Research, Research Paper number 212, UNHCR, Geneva, Switzerland, 2011.

[11] M. Mirza, "Resettlement for disabled refugees," in Forced Migration Review 35: Disability and Displacement, 2010. 
[12] K. Ward, N. Amas, and J. Lagnado, Supporting Disabled Refugees and Asylum Seekers: Opportunities for New Approaches, Metropolitan Support Trust, London, UK, 2008.

[13] Z. Ciupijus, "Ethical pitfalls of temporary labour migration: a critical review of issues," Journal of Business Ethics, vol. 97, supplement 1, pp. 9-18, 2011.

[14] M. Burawoy, "The functions and reproduction of migrant labor: comparative material from Southern Africa and the United States," American Journal of Sociology, vol. 81, no. 5, pp. 1050-1087, 1976.

[15] C. Hahamovitch, "Creating perfect immigrants: guestworkers of the world in historical perspective," Labor History, vol. 44, no. 1, pp. 69-94, 2003.

[16] Australian Government Department of Immigration and Citizenship, "Temporary business (long stay)—standard business sponsorship (subclass 457)," http://www.immi.gov.au/skilled/ skilled-workers/sbs/eligibility-employee.htm.

[17] B. Kinnaird, "Current issues in the skilled temporary subclass 457 visa," People and Place, vol. 14, no. 2, pp. 49-65, 2006.

[18] B. Deegan, Visa Subclass 457 Integrity Review: Final Report, Canberra, Australia, 2008.

[19] A. Weathers, C. Minkovitz, P. O’Campo, and M. Diener-West, "Health services use by children of migratory agricultural workers: exploring the role of need for care," Pediatrics, vol. 111, no. 5, pp. 956-963, 2003.

[20] J. F. Kilanowski and N. A. Ryan-Wenger, "Health status in an invisible population: carnival and migrant worker children," Western Journal of Nursing Research, vol. 29, no. 1, pp. 100120, 2007.

[21] S. Berman, "Health care research on migrant farm worker children: why has it not had a higher priority?" Pediatrics, vol. 111, no. 5, pp. 1106-1107, 2003.

[22] L. G. Bedolla, "Intersections of inequality: understanding marginalization and privilege in the post-civil rights era," Politics \& Gender, vol. 3, no. 2, pp. 232-248, 2007.

[23] D. L. Morgan and R. K. Morgan, Single-Case Research Methods for the Behavioral and Health Sciences, Sage Publications, London, UK, 2008.

[24] R. A. Sayer, Realism and Social Science, Sage Publications, London, UK, 2000.

[25] W. L. Neuman, Social Research Methods: Quantitative and Qualitative Methods, Allyn \& Bacon, Needham Heights, Mass, USA, 2000.

[26] R. K. Yin, Case Study Research: Design and Methods, Sage Publications, Thousand Oaks, Calif, USA, 2003.

[27] M. Q. Patton, Qualitative Research and Evaluation Methods, Sage Publications, Thousand Oaks, Calif, USA, 2002.

[28] N. Brackertz, "Who is hard to reach and why?" ISR Working Paper, Institute for Social Research, Swinburne University, Melbourne, Australia, 2007.

[29] H. Lutz, The New Maids: Transnational Women and the Care Economy, Zed Books, London, UK, 2011.

[30] OECD, "International migrant remittances and their role in development," International Migration Outlook, part III, OECD, Paris, France, 2006, http://www.oecd.org/dataoecd/ 61/46/38840502.pdf.

[31] S. Elgersma, Temporary Foreign Workers, PRB 07-11E, Parliament of Canada, Political and Social Affairs Division, Ottawa, Canada, 2007, http://www.parl.gc.ca/Content/LOP/ ResearchPublications/prb0711-e.pdf.

[32] M. Golosov and A. Tsyvinski, "Designing optimal disability insurance: a case for asset testing," Journal of Political Economy, vol. 114, no. 2, pp. 257-279, 2006.
[33] R. Haveman and B. Wolfe, "Chapter 18 the economics of disability and disability policy," Handbook of Health Economics, vol. 1, pp. 995-1051, 2000.

[34] J. Gothard and C. Fox, "Consign disability discrimination to the bin," The Australian, November 2008, http://www.theaustralian.com.au/news/opinion/consign-disability-discrimination-to-the-bin/story-e6frg6zo-1111118052359.

[35] ABC Radio National, "Disabled migrants still not welcome," National Interest, November 2011, http://www.abc.net.au/ radionational/programs/nationalinterest/disabled-migrantsstill-not-welcome/3636278.

[36] Disability Services Commission, "Eligibility for specialist disability services," Government of Western Australia, Perth, Australia, 2011, http://www.disability.wa.gov.au/dscwr/ _assets/main/instructional/documents/pdf/eligibility_for_specialsit_disability_services.pdf.

[37] W. W. Hartup and S. G. Moore, "Early peer relations: developmental significance and prognostic implications," Early Childhood Research Quarterly, vol. 5, no. 1, pp. 1-17, 1990.

[38] W. S. Barnett, "Long-term effects of early childhood programs on cognitive and school outcomes," The Future of Children, vol. 5, no. 3, pp. 25-50, 1995.

[39] L. Briskman, D. Zion, and B. Loff, "Care or collusion in asylum seeker detention," Ethics and Social Welfare, vol. 6, no. 1, pp. 37-55, 2012.

[40] National Ethnic Disability Alliance, "Data confirms higher rate of disability amongst migrants," NEDA, Melbourne, Australia, March 2011, http://www.neda.org.au/page/media releases.html. 


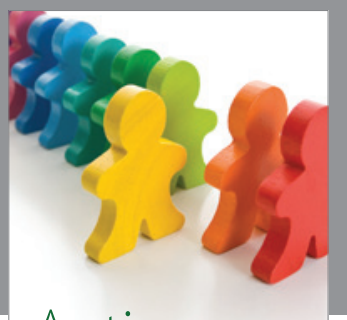

Autism

Research and Treatment
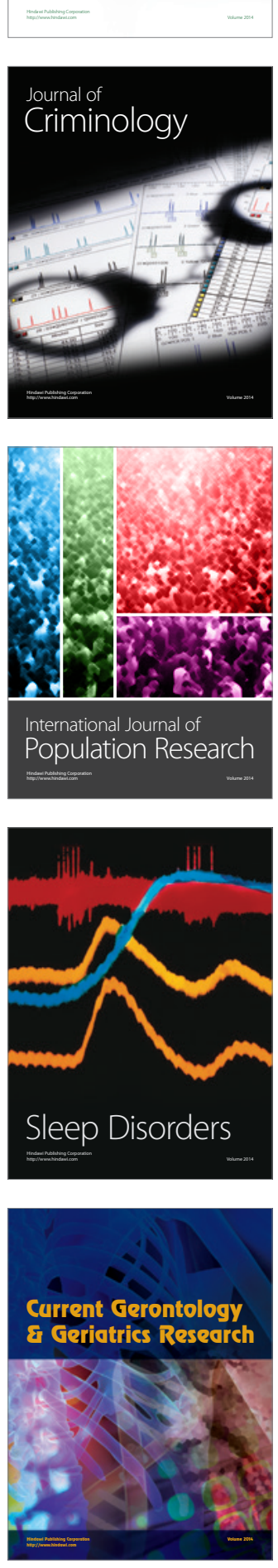
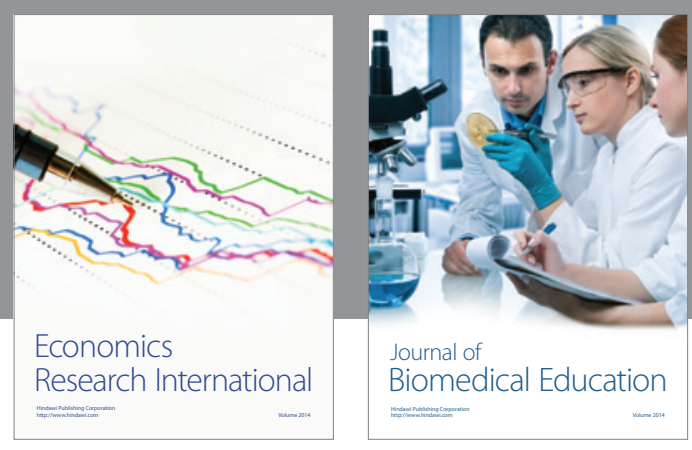

Journal of

Biomedical Education

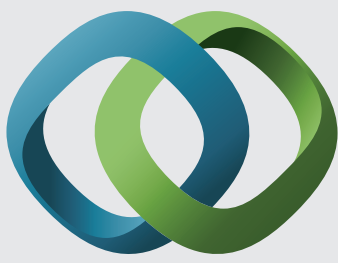

\section{Hindawi}

Submit your manuscripts at

http://www.hindawi.com
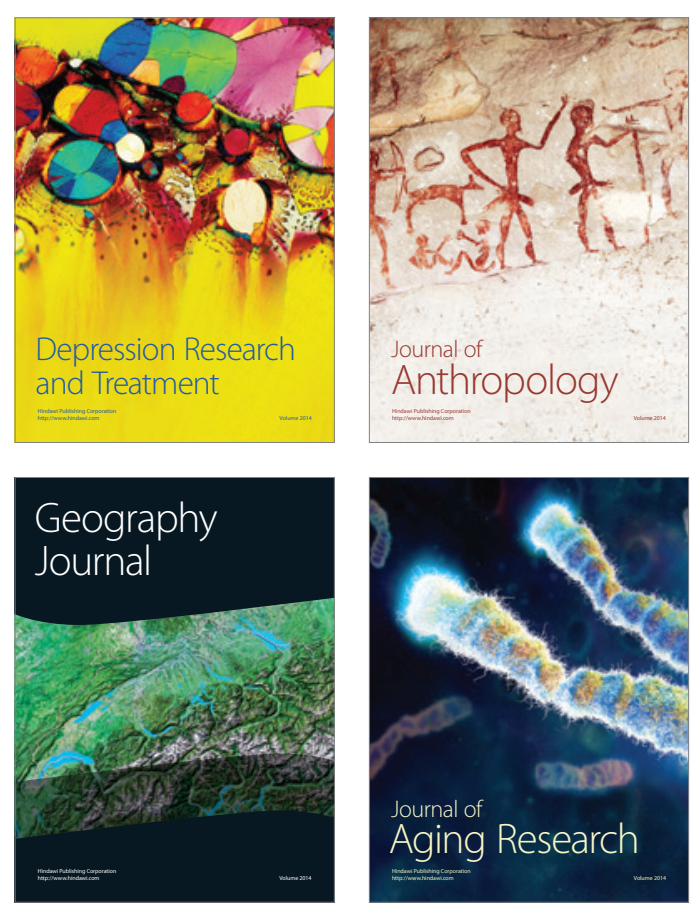

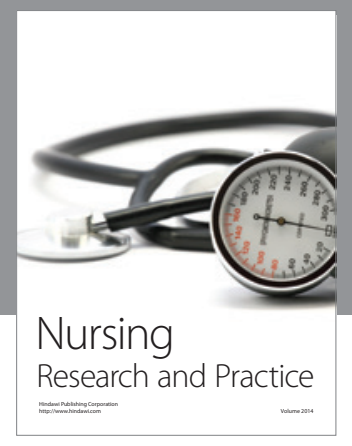

Nursing

Research and Practice

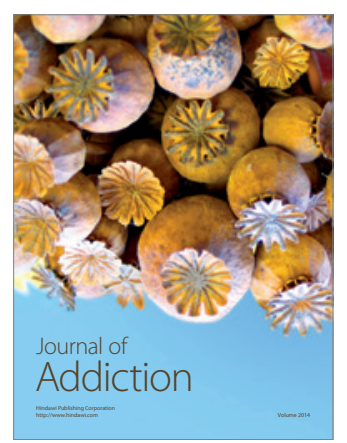

Child Development

Research

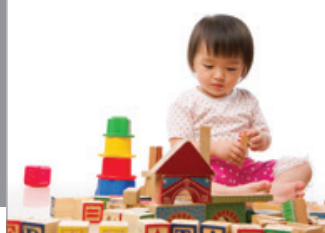

迥
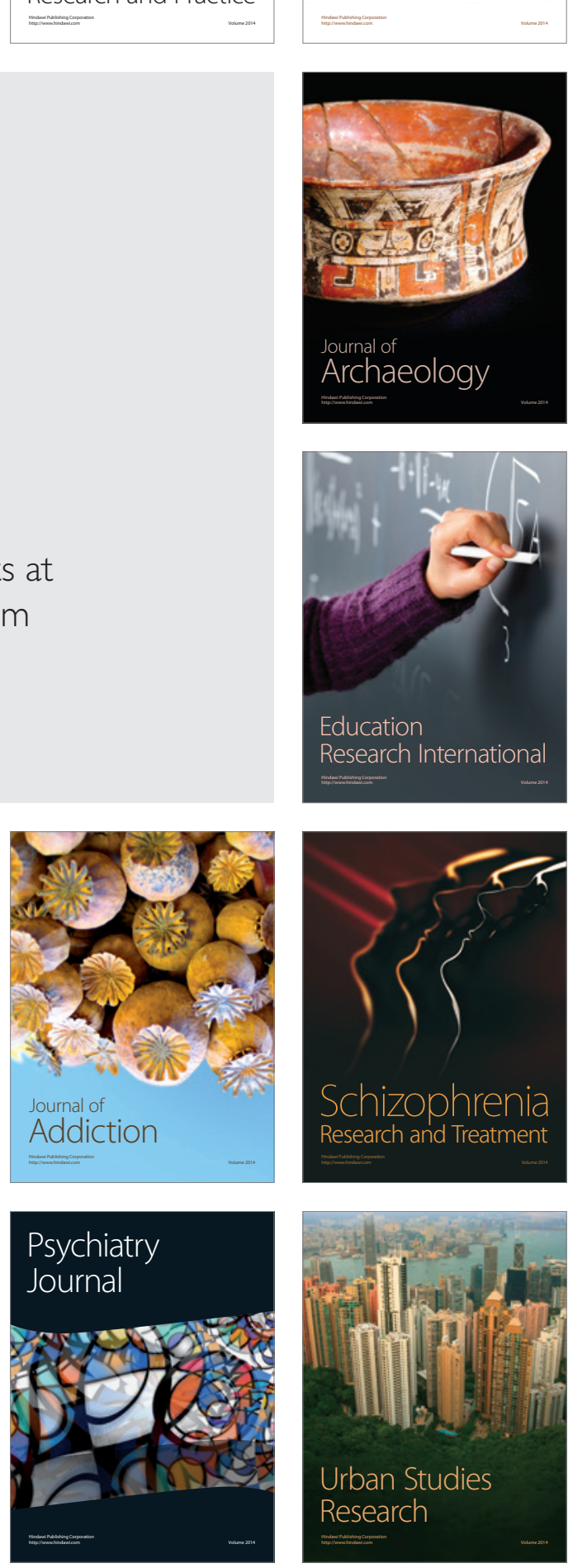